Research Paper

\title{
New Adipose Tissue Formation by Human Adipose- Derived Stem Cells with Hyaluronic Acid Gel in Immunodeficient Mice
}

\author{
Shu-Hung Huang $1,2,3,4$, Yun-Nan Lin³, Su-Shin Lee2,3,4, Chee-Yin Chai5, Hsueh-Wei Chang6, Tsai-Ming Lin³, \\ Chung-Sheng Lai ${ }^{2,3,4}$, Sin-Daw Lin $2,3,4, \mathbb{}$ \\ 1. Graduate Institute of Medicine, College of Medicine, Kaohsiung Medical University, Kaohsiung, Taiwan \\ 2. Center for Stem Cell Research, Kaohsiung Medical University, Kaohsiung, Taiwan \\ 3. Division of Plastic Surgery, Department of Surgery, Kaohsiung Medical University Hospital, Kaohsiung Medical University, Kaohsiung, Taiwan \\ 4. Department of Surgery, Faculty of Medicine, College of Medicine, Kaohsiung Medical University, Kaohsiung, Taiwan \\ 5. Department of Pathology, Kaohsiung Medical University Hospital, Kaohsiung, Taiwan \\ 6. Department of Biomedical Science and Environmental Biology, Kaohsiung Medical University, Kaohsiung, Taiwan
}

$\triangle$ Corresponding author: Sin-Daw Lin, M.D. Division of Plastic Surgery, Department of Surgery, Kaohsiung Medical University Hospital, 100 Tzyou 1st Rd. Kaohsiung 80708, Taiwan. Tel: +886 7 3208176; fax: +886 7 3111482; E-mail: sidalin@kmu.edu.tw

( ) Ivyspring International Publisher. This is an open-access article distributed under the terms of the Creative Commons License (http://creativecommons.org/ licenses/by-nc-nd/3.0/). Reproduction is permitted for personal, noncommercial use, provided that the article is in whole, unmodified, and properly cited.

Received: 2014.06.23; Accepted: 2014.12.30; Published: 2015.01.08

\begin{abstract}
Background: Currently available injectable fillers have demonstrated limited durability. This report proposes the in vitro culture of human adipose-derived stem cells (hASCs) on hyaluronic acid (HA) gel for in vivo growth of de novo adipose tissue.

Methods: For in vitro studies, hASCs were isolated from human adipose tissue and were confirmed by multi-lineage differentiation and flow cytometry. hASCs were cultured on HA gel. The effectiveness of cell attachment and proliferation on HA gel was surveyed by inverted light microscopy. For in vivo studies, HA gel containing hASCs, hASCs without HA gel, HA gel alone were allocated and subcutaneously injected into the subcutaneous pocket in the back of nude mice $(n=6)$ in each group. At eight weeks post-injection, the implants were harvested for histological examination by hematoxylin and eosin (H\&E) stain, Oil-Red $\mathrm{O}$ stain and immunohistochemical staining. The human-specific Alu gene was examined.

Results: hASCs were well attachment and proliferation on the HA gel. In vivo grafts showed well-organized new adipose tissue on the HA gel by histologic examination and Oil-Red $\mathrm{O}$ stain. Analysis of neo-adipose tissues by PCR revealed the presence of the Alu gene. This study demonstrated not only the successful culture of hASCs on HA gel, but also their full proliferation and differentiation into adipose tissue.

Conclusions: The efficacy of injected filler could be permanent since the reduction of the volume of the HA gel after bioabsorption could be replaced by new adipose tissue generated by hASCs. This is a promising approach for developing long lasting soft tissue filler.
\end{abstract}

Key words: human adipose-derived stem cells, adipose tissue

\section{Introduction}

Approximately 2 million soft tissue filler procedures were performed in the United States in 2012[1]. Thus, it is more important than ever to study on soft tissue filler. Soft tissue augmentation is a continuing problem in plastic and reconstructive surgery due to not long-lasting. Ideally, injectable filler material should be safe, effective, long-lasting, and biocompatible [2]. Injectable filler is advantageous not only 
because it minimizes the risk of operative infections, scarring, and operative costs, but also because multiple defective sites can be filled simultaneously. Recent studies have evaluated the use of long-lasting fillers for adipose tissue engineering.

Advantages of fat grafting include biocompatibility, versatility, stability, and natural appearance $[3$, $4,5,6]$. Adipose tissue can also be obtained safely and with minimal donor site morbidity by using minimally invasive liposuction techniques $[7,8,9]$. However, cosmetic outcomes are unpredictable due to unresolved problems such as fat necrosis after grafting and high resorption rate, which can reportedly exceed 50 percent [10]. Despite the improved outcomes obtained by recent refinements in conventional fat grafting techniques [11, 12], improved optimal fillers are still needed.

A long-lasting filler should incorporate a biocompatible scaffold that defines the required volume, promotes host integration, and degrades as it is replaced by new adipose tissue. Therefore, scaffolds must include naturally derived or synthetic tissue substitutes. Naturally derived materials include hyaluronic acid [13, 14], collagen [15, 16, 17], chitosan [18, 19], and alginate [20, 21]; synthetic materials include polyglycolic acid (PGA) [22, 23, 24], poly(DL-lactide-co-glycolide) (PLGA) [23, 25, 26], poly(ethylene glycol) diacrylate (PEGA) $[27,28]$ and so on. All these materials are designed to minimize immune rejection and resorption. Thus, key factors in filler design are mechanical properties, degradation characteristics, immunogenicity, and cellular response to the scaffold [29].

Hyaluronic acid (HA)-based gels are also widely used injectable materials [2]. The most popular is

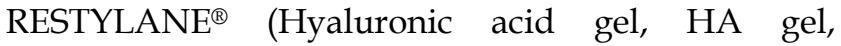
http://www.restylaneusa.com) [30], a non-animal, stabilized hyaluronic acid (NASHA) produced by fermentation in equine streptococci cultures. Various filler products are differentiated by hyaluronic acid concentration, chemical cross-linking, and particle size. HA gel has good biocompatibility and virtually no immunogenicity [31]. However, because catabolic processes, which are mediated by receptor binding and intracellular degradation [32], persist for 6 to 12 months after injection [33], repeated injections are needed for long-term results.

Recent in vivo [34, 35] and in vitro [36] studies of hASCs have evaluated the use of various biocompatible scaffolds for adipose tissue engineering. Adipose tissue has also been successfully engineered in predefined shapes and in three dimensions by the authors and other researchers [35, 37]. An effective tissue-engineering strategy must ensure that, as cells grow, the scaffolding material degrades or is absorbed and eventually yields a new mass of adipose tissue to maintain the tissue contour [7].

Hyaluronic acid-based materials have been studied for engineering various tissues, including skin [38], adipose tissue [13], cartilage [39], and bone [40]. These scaffolding materials are apparently suitable culture carriers, and in vivo animals' models reveal full maturation into adipocytes [41]. We hypothesized that de novo adipose tissue formation could be achieved by pure hyaluronic acid scaffolding cell delivery and tissue engineering. Therefore, this study evaluated a technique for culturing hASCs on HA gel to obtain soft tissue filler that was sufficiently long-lasting for engineering adipose tissue.

\section{Materials and methods}

\subsection{Isolation of human adipose-derived stem cells from adipose tissue}

With patient's informed consent and IRB approved by the review board of Kaohsiung Medical University Hospital (KMUH-IRB-960443), the hASCs were isolated from subcutaneous adipose tissue from female donors who underwent transverse rectus abdominis myocutaneous (TRAM) flap for breast reconstruction. The hASCs were isolated by standard protocol with some modifications as follows [42]. Tissues were washed with PBS containing $1 \%$ penicillin/streptomycin (P/S) (Gibco-BRL, USA). After removing red blood cells, the human adipose tissue was digested overnight in PBS supplemented with $0.01 \%$ $(w / v)$ collagenase type I (Gibco-BRL) at $37{ }^{\circ} \mathrm{C}$. The suspension was centrifuged at 1200 RPM for $10 \mathrm{~min}$, and the pellet was washed several times with PBS. The isolated cells were incubated in K-SFM (Invitrogen, USA) supplemented with $10 \%$ fetal bovine serum (FBS, Gibco-BRL) and $1 \% \mathrm{P} / \mathrm{S}$ at $37^{\circ} \mathrm{C}$ under $5 \% \mathrm{CO}_{2}$. The hASCs were tested for potential multi-lineage differentiation of adipogenesis, osteogenesis, and chondrogenesis as previous report [37, 42, 43, 44].

\subsection{Flow cytometry}

The phenotype of hASCs was analyzed by flow cytometry using a Partec flow cytometry. The following mAbs were used : CD34 (1:200, BioLegend, USA), CD44 (1:200, BioLegend, USA), CD45 (1:200, BioLegend, USA), CD90 (1:200, BioLegend, USA), CD105 (1:200, BioLegend, USA). Freshly isolated hASCs were incubated with primary antibody in 200 $\mu 1$ PBS for 20 minutes, followed by another incubation with FITC-conjugated secondary antibody in $200 \mu \mathrm{l}$ for 20 minutes in the dark. After two wash steps, the cells were re-suspended in $500 \mu \mathrm{l}$ PBS and analyzed. 


\subsection{Cell seeding in HA gel, proliferation and MTT assay}

The $4^{\text {th }}$ passages hASCs $\left(2 \times 10^{7}\right.$ cells $\left./ \mathrm{ml}\right)$ in $1 \mathrm{ml}$ tube was centrifuged at 1200rpm for $5 \mathrm{~min}$ to have a high-density cell pellet. This pellet was resuspended in $0.2 \mathrm{ml}$ DMEM. hASCs were labeled with chloromethyl-benzamido 1,1'-dioctadecyl-3,3,3',3'- tetramethylindocarbocyanine perchlorate (CellTracker ${ }^{\circledR}$ CM-DiI; Invitrogen, Life Technologies) according to the manufacturer's instruction for visualization. Cell suspension $0.2 \mathrm{ml}$ was mixed with $0.2 \mathrm{ml}$ sterile RESTYLANE $^{\circledR}$ and placed in a 6-well ultra low culture plate (Corning, USA). Medium was changed every two day. Adhesion of hASCs on the HA gel surface was evaluated under inverted light microscopy (ECLIPSE TS100 inverted microscope, Nikon Corporation). In proliferation studies, two groups HA-hASCs and hASCs alone group were allocate to MTT assay. The MTT ( (3-(4,5-dimethylthiazol-2-yl)2,5-diphenyltetrazolium bromide)) substrate is prepared in a Phosphate buffered saline (PBS), added to cells in culture, final concentration of $0.5 \mathrm{mg} / \mathrm{ml}$, and incubated for 4 hours at $37^{\circ} \mathrm{C}$. After use Dimethyl sulfoxide (DMSO) to each well to dissolve formazan crystals. The quantity of formazan (presumably directly proportional to the number of viable cells) is measured by recording changes in absorbance at 570 $\mathrm{nm}$ using a plate reading spectrophotometer.

\subsection{Animal models}

Guidelines established by the Laboratory Animal Center of Kaohsiung Medical University for the care and use of laboratory animals were observed during all animal experiments. Immunodeficient male mice (BALB/cAnNCrj-nu/nu, six weeks old $20 \mathrm{gm}$ ) were purchased from BioLASCO Taiwan Co. Ltd. The another hASCs were cultured in adipogenic induction medium (IDI-I medium and insulin cocktail) for 2 weeks in vitro as previous report, with CM-DiI stain [37]. This study were allocate with three groups, one is HA-hASCs group, inducted hASCs $\left(0.2 \mathrm{ml}, 1 \times 10^{7}\right.$ cells $/ \mathrm{mL}$ ) were mixed with culture medium (DMEM $0.2 \mathrm{ml})$ and HA gel $(0.2 \mathrm{ml})$ then injected into the subcutaneous pockets in the back of immunodeficient mice using a $1 \mathrm{ml}$ syringe with 19-gauge needle under analgesia. The other two groups were inducted hASCs alone group $\left(0.2 \mathrm{ml}, 1 \times 10^{7}\right.$ cells $/ \mathrm{mL}$ with $0.2 \mathrm{ml}$ DMEM) and HA gel alone group (0.2ml HA gel with $0.2 \mathrm{ml}$ DMEM). Each mice received one samples $(\mathrm{n}=6$ in each group).

\subsection{Hematoxylin-eosin stain, Oil-Red $O$ stain and immunohistochemical staining}

All mice $(n=18)$ were sacrificed at 8 weeks postoperatively with overdose analgesic. The implants were carefully harvested, and the transplanted mixture was weighed using a top-loading balance (Precisa XB 320M). The tissue samples were collected and fixed in $4 \%$ paraformaldehyde, perpendicular section was done of $8 \mu \mathrm{m}$ thickness in optimal cutting temperature (OCT) embedded. Stain with hematoxylin-eosin and Oil-Red $\mathrm{O}$ stain according to routine histologic protocol. The tissue sections were observed by microscopy (Nikon, Ti-U, USA).

The specimens were fixed in $10 \%$ formalin and subsequently embedded in paraffin. The paraffin-embedded tissues were cut with microtome at $3 \mu \mathrm{m}$. Slides were deparaffinized and hydration and treated with $0.1 \mathrm{M}$ citrate buffer $(\mathrm{pH}$ 6.0) for CD44 in autoclave $121^{\circ} \mathrm{C}$ at $8 \mathrm{~min}$. By using $3 \%$ hydrogen peroxide for 5 minutes to blocking endogenous peroxidase activity at room temperature. After wash with Tris buffer solution (TBS), the sections were incubated with the primary antibodies anti-rat CD44 (1:100; BioLegend, San Diego, CA) at $4^{\circ} \mathrm{C}$ overnight. The sections were washed with TBS. Biotinylated second antibody and peroxidase-conjugated streptavidin for used REAL Envision Detection System (DAKO, Denmark) were applied for 30 minutes each. Finally, sections were incubated in 3,3'-diaminobenzidine for 5 minutes, followed by hematoxylin counterstaining and mounting with Entellan (Merck, HX247305).

\subsection{Alu Polymerase chain reaction (PCR)}

Alu PCR is a method of comparing human and nonhuman tissue. Tissue DNA was purified by DNeasy tissue kit (Qiagen, Valencia, CA, USA) following the manufacturer's manual. After genomic DNA extraction, it is suggested to check its quality using agarose gel electrophoresis. Alu PCR was conducted using the PCR-based Alu-Human DNA Typing kit (EDVOTEK ${ }^{\circledR}$; The Biotechnology Education Company $^{\circledR}$, Bethesda, MD, USA). PCR conditions were the following: $94^{\circ} \mathrm{C}(1 \mathrm{~min})$; four cycles of $94^{\circ} \mathrm{C}$ (15 s), $64^{\circ} \mathrm{C}(15 \mathrm{~s}), 70^{\circ} \mathrm{C}(15 \mathrm{~s})$; four cycles of $94^{\circ} \mathrm{C}(15$ s), $61^{\circ} \mathrm{C}(15 \mathrm{~s}), 70^{\circ} \mathrm{C}(15 \mathrm{~s})$; four cycles of $94^{\circ} \mathrm{C}(15 \mathrm{~s})$, $58^{\circ} \mathrm{C}(15 \mathrm{~s}), 70{ }^{\circ} \mathrm{C}(15 \mathrm{~s}) ; 60$ cycles of $94^{\circ} \mathrm{C}$ for $(15 \mathrm{~s})$, $55^{\circ} \mathrm{C}(15 \mathrm{~s}), 70{ }^{\circ} \mathrm{C}(15 \mathrm{~s}) ; 94{ }^{\circ} \mathrm{C}(1 \mathrm{~min})$ and $60^{\circ} \mathrm{C}(5$ min). PCR products were electrophoretically separated electrophoresed on a $2.5 \%$ agarose gel and visualised by ethidium bromide staining.

\section{Results}

\section{1. hASCs have multilineage differentiation capabilities, HA gel did not inhibit the hASCs proliferation in vitro}

The hASCs were well-differentiated into three lineages (adipocytes, osteocytes, and chondrocytes) (Fig. 1). For cell proliferation study, the cells were 
incubated with HA gel for 1,3,7 days. Figure 2 shows the hASCs mixed well in the HA gel. After 7 days, the number of hASCs in the HA gel had increased and showed no significantly different with hASCs alone group. This indicated the HA gel didn't affect the hASCs proliferation.

\subsection{Flow cytometry finding comparable with ASCs}

Black histograms represent the fluorescence from control cells incubated with only FITC-conjugated secondary antibody. Red histograms represented the cells incubated with relevant primary antibody. Flow cytometric study of hASCs revealed CD45-, CD34-, CD44+, CD90+, CD105+ (Fig. 1).

\section{3 new adipose tissue formed in HA gel with hASCs group}

To assess in vivo cell proliferation, adipogenic differentiation, and new adipose tissue formation, HA gel with hASCs or HA gel with culture medium was subcutaneously injected into nude mice. The injected HA gel mixture was easily identified throughout the eight-week experiment and no skin necrosis or inflammatory reaction was noted when the mice were sacrificed at 8 weeks (Fig. 3, above, left). The experimental group revealed soft round deposits of fat tissue (average size, $0.6^{*} 0.5^{*} 0.3 \mathrm{~cm}$ ) surrounding the residual turbid HA gel, and no signs of fibrosis or cystic space were noted (Fig. 3, below, left). Besides, in gross view, capillary caliber was increased, and neovascularization was noted near the treated area (Fig. 3, below, left). In the control group, the residual clear HA gel was observed in the subcutaneous area (average size, $0.3^{\star} 0.4^{\star} 0.2 \mathrm{~cm}$ ) (Fig. 3, above, right and below, right). Weight evaluation was not performed because the borders of the specimens were not clearly delineated.
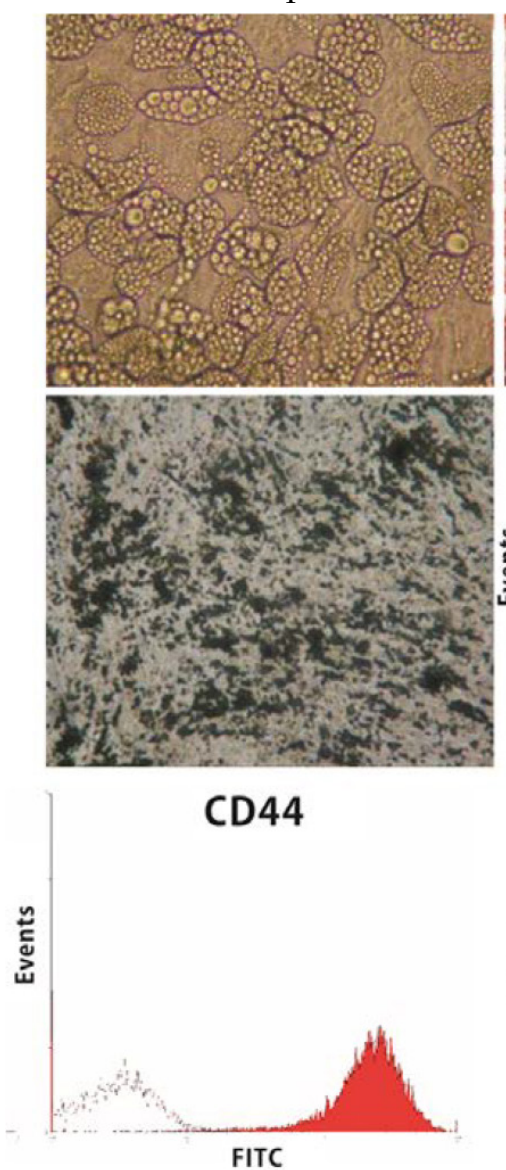
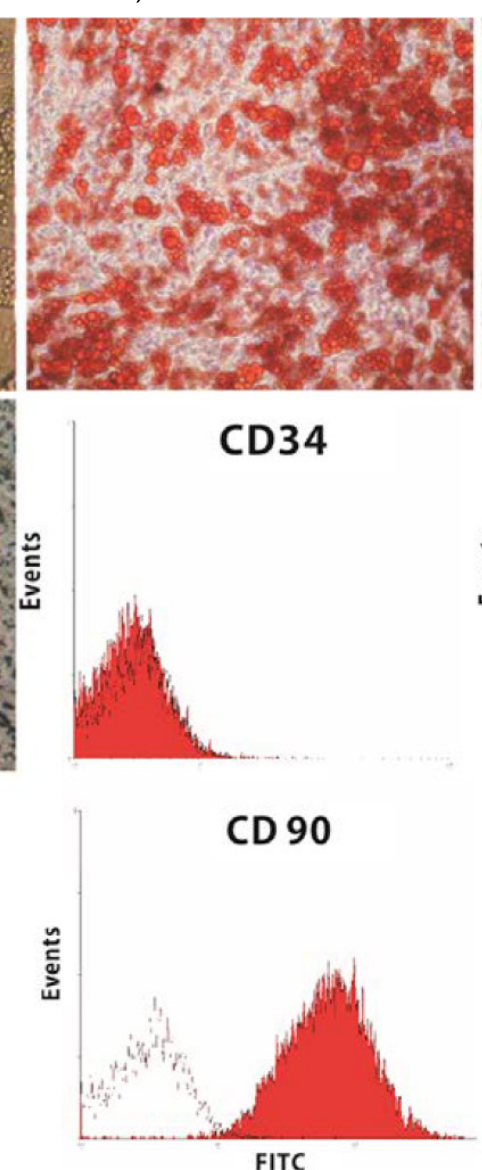

FITC

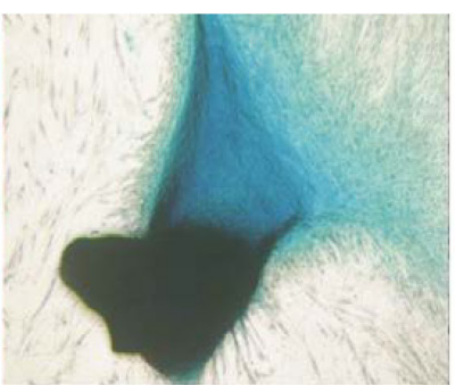

CD45

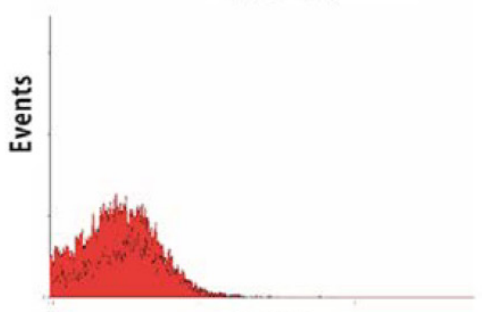

FITC

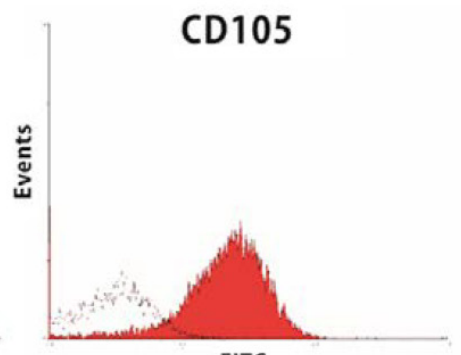

FITC

Fig. 1. The hASCs were well-differentiated into three cell lineages. Lipid vacuole formation after 2 weeks culture of hASCs in adipogenic medium (upper row, left). Positive Oil-Red O stain (X200) (upper row, middle). Positive Alcian Blue stain after 2-week culture of hASCs in chondrogenic medium (X200) (upper row, right). Positive von Kossa stain after 4-week culture of hASCs in osteogenic medium (X200) (middle row, left). Flow cytometric analysis on hASCs for the expression of CD34, CD45, CD44, CD90, and CD105 was performed (Red). Cells stained with Isotype control lgG were examined as a control (black). 

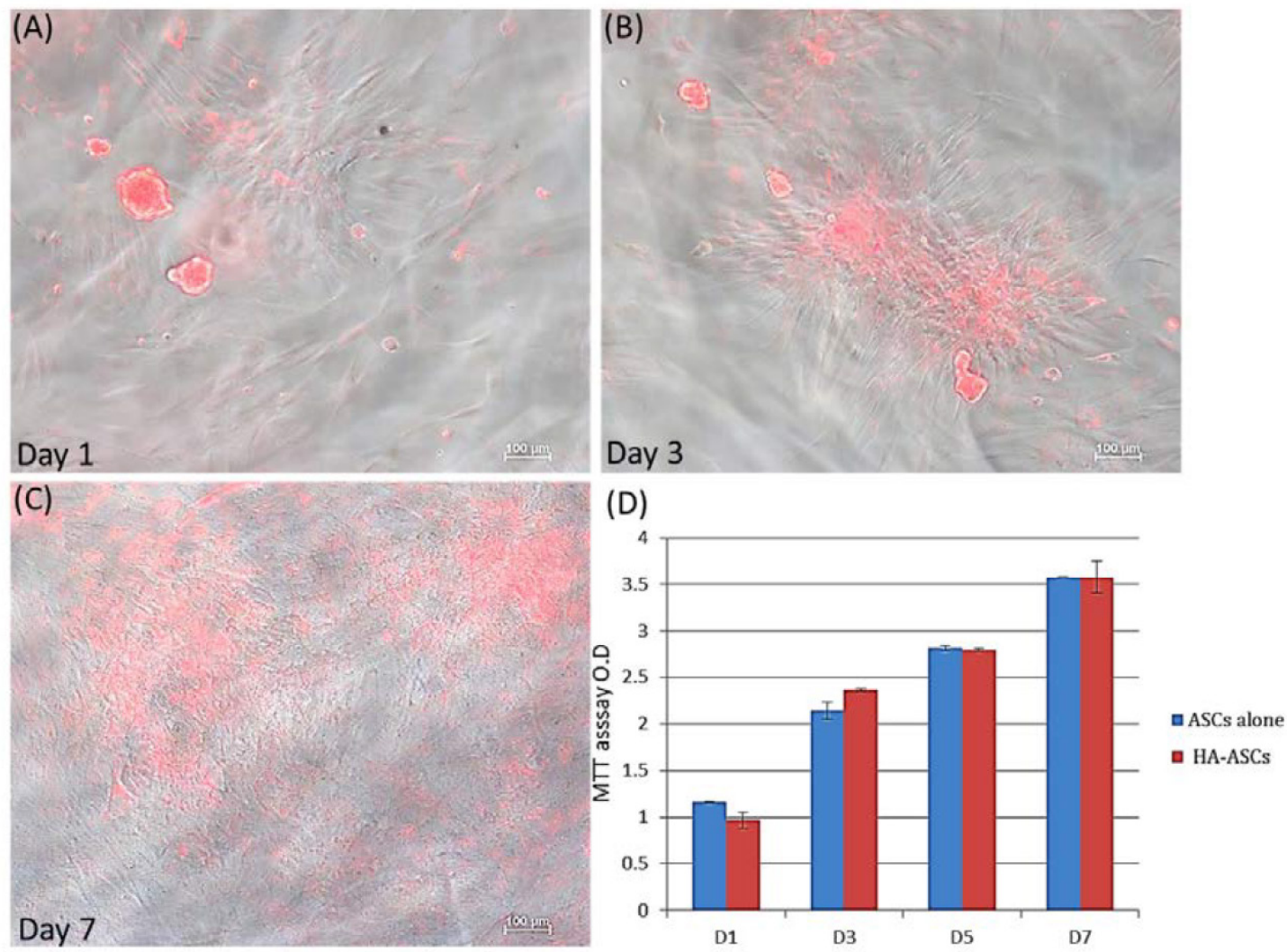

Fig. 2. Inverted light microscope image showing hASCs seeding in HA gel. hASCs proliferate and aggregate in HA gel on Day 1,3,7 (X100) (red color indicated hASCs with CM-Dil stain). An MTT assay was used to check hASCs cell proliferation in HA gel. No significantly difference between HA-hASCs and hASCs alone group in MTT assay. Error bars indicated deviation.

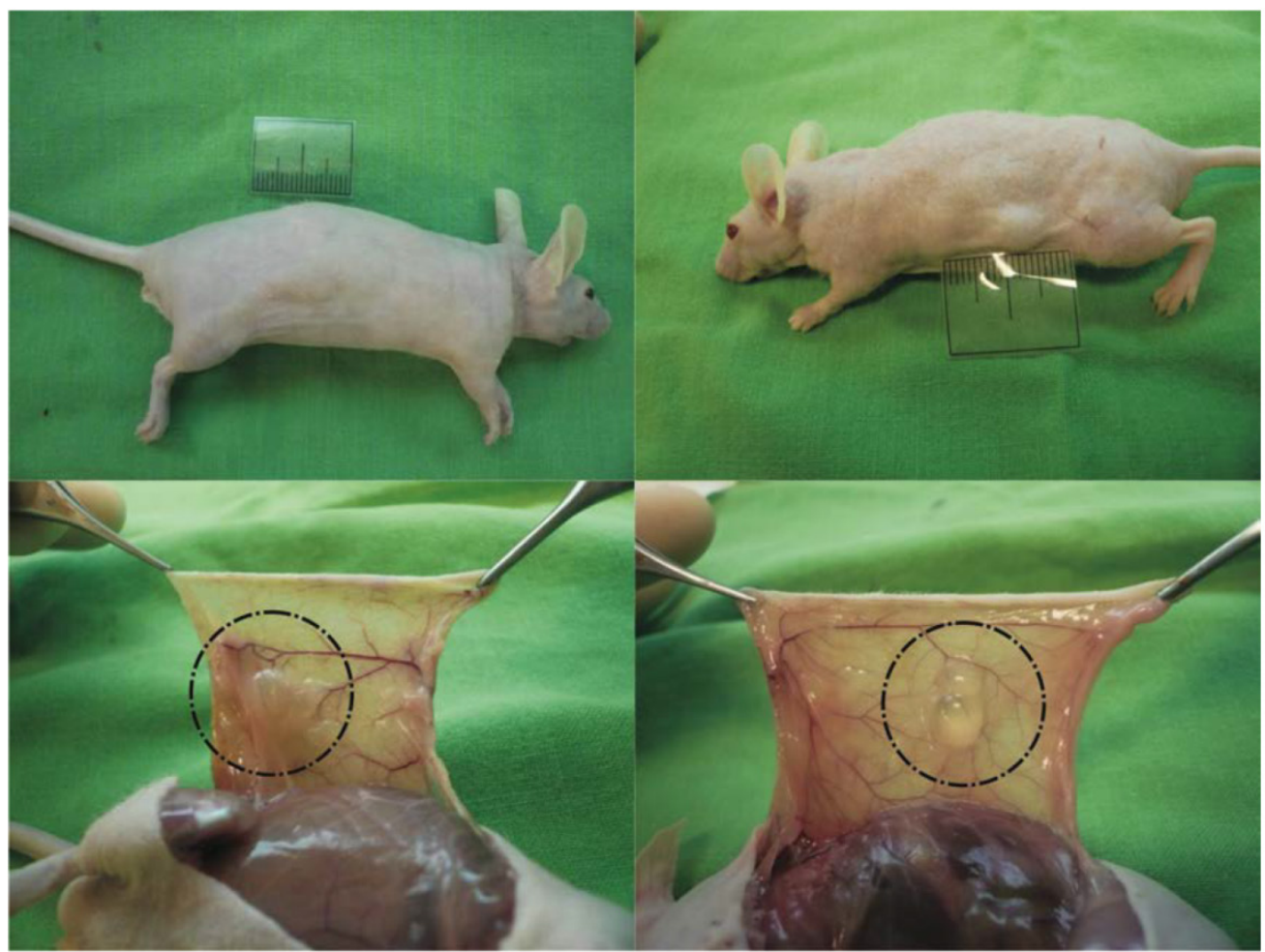

Fig. 3. Macroscopic appearance of grafts in nude mice. Suspension of HA gel containing hASC was subcutaneously injected into the back of each nude mouse. (Left) New adipose tissue formation was noted near the residual HA gel at eight weeks after injection. (Right) In the control group, the residual clear $\mathrm{HA}$ gel was noted in subcutaneous areas. The ruler represents $2 \mathrm{~cm}$. 


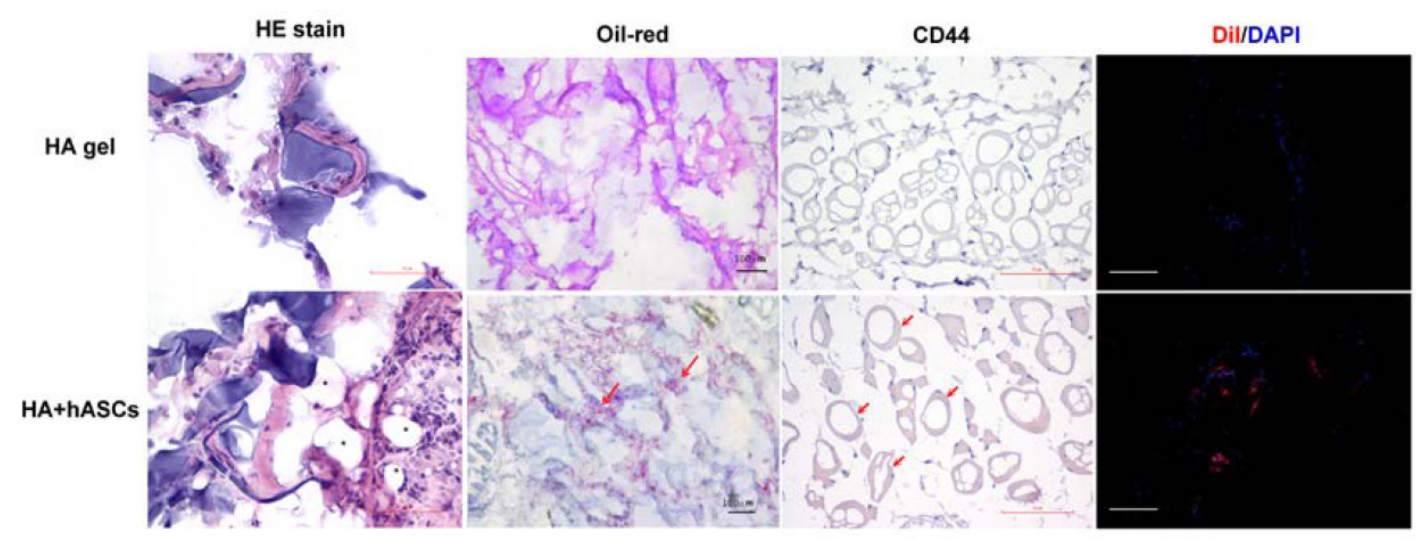

Fig. 4. Histological examination of the grafts stained by hematoxylin-eosin stain eight weeks after injection of suspension of HA gel with hASCs revealed newly formed adipose tissue. The black stars $\left(^{*}\right)$ indicate adipose tissue (scale bar $50 \mu \mathrm{m}$ ). Oil-Red $\mathrm{O}$ stain (red arrows) revealed the gradual replacement of degraded HA gel with newly formed adipose tissue (red stain) (scale bar $100 \mu \mathrm{m}$ ). In the immunohistochemical stain showed CD44 positive cell marker and CM-Dil positive in newly adipose tissue (scale bar $50 \mu \mathrm{m}, 100 \mu \mathrm{m}$ respectively).

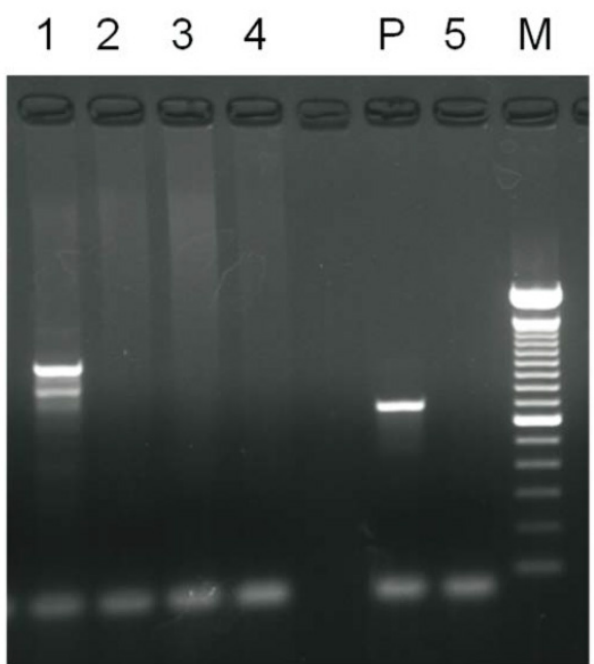

Fig. 5. Results of PCR analysis of Alu gene in graft specimens. 1 was HA gel with hASCs graft. 2 was HA gel only. 3 was hASCs only. 4 was HA gel with medium. 5 was control group. $\mathrm{P}$ was positive control.

\section{4 newly adipose tissues were positive with Oil-Red O, CD44 and CM-Dil stain}

The HA gel with hASCs groups exhibited well-organized adipose tissue formation intermingled with HA gel in H\&E stain (Fig. 4). Frozen sections of graft specimens stained with Oil-Red O demonstrated that these newly formed adipose tissues were rich in lipid deposit. In the immunohistochemical stain showed CD44 positive cell marker and CM-DiI positive in newly adipose tissue (Fig. 4).

\subsection{Alu gene expressed in newly formed adipose tissue}

The neovascularization suggested that hASC-loaded HA gel could proliferate to adipogenesis and form new adipose tissue. To verify the source of newly formed adipose tissue in the nude mice, the
Alu gene was studied. Analysis of newly formed adipose tissues by PCR revealed the presence of the Alu gene (Fig. 5).

\section{Discussion}

Soft tissue fillers are widely used to correct congenital defects [45] and acquired soft tissue defects such as those resulting from traumatic lesion, tumor resection, and severe burns [46]. Recently, soft-tissue fillers have been used for rejuvenation and to treat soft-tissue defects [47, 48, 49, 50, 51]. Autologous free fat grafting is widely used for filling soft-tissue and contour defects because of its relatively low cost, easy harvest, low donor site morbidity, and lack of allergic reaction. However, average volume loss after fat autotransplants is reportedly 50 percent $[10,52]$. Each of the various fillers (e.g., hyaluronic acid-based filler, collagen, calcium-based microspheres gel) now available on the market, has advantages and disadvantages. Although Lowe et al. [53] showed that hyaluronic acid filler has a low risk of hypersensitive reaction, another comparative study of Restylane ${ }^{\circledR}$ and Zyplast ${ }^{\circledR}$ reported an overall increase in the incidence of severe bruising, swelling, and pain [2].

A study by Inamed Corporation indicated that common adverse side effects of human collagen filler include cold-like symptoms, flu-like symptoms and urinary tract infection [54]. In Tzikas et al., a 52-month follow-up study of patients treated with calcium hydroxylapatite filler indicated that $80 \%$ of the patients experienced side effects at 12 months post-treatment [55]. Notably, hydroxylapatite filler is also radiopaque and may interfere with facial radiography [2]. Accordingly, cell-based adipose tissue engineering is a newly emerging method with substantial advantages over current treatment methods.

Cell-based adipose tissue engineering studies have focused on using various scaffolds as cell carri- 
ers to obtain the appropriate shapes and dimensions of reparative tissues. Essential properties of such scaffolds are controlled degradation and lack of immunogeneticity or cytotoxicity [56]. Hyaluronic acid is an essential component of the extracelluar matrix of human tissue. The extracelluar matrix provides a microenvironment for maintaining cell homeostasis and for differentiating tissue properties [57, 58]. Furthermore, scaffolding can be used as a cell support device upon which cell are seeded, otherwise like our data showed in figure 5, the injected hASCs were disappear and cannot detect by Alu gene.[59] The hASCs are an attractive source of cells for cell-based tissue engineering for adipogenesis [34, 37, 60]. Thus, scaffold with hASCs is become mutually beneficial for adipose tissue engineering.

The many advantages of hASCs include the ability to obtain large amounts of donor tissue with relatively mild patient discomfort and with limited donor site morbidity. They provide a rich source of multipotent stem cells that can be expanded to large numbers in vitro [42, 44,61]. In our study, the cell surface markers were expressed positive for CD44, CD90, CD105. These results are the same as Zannettino et al report [62]. Since CD44 is the primary receptor for hyaluronic acid, its expression by hASCs may influence cell signaling pathways and cellular functions [63, 64]. This study therefore injected co-cultured hyaluronic acid into subcutaneous areas of immune-deficient mice to provide a suitable microenvironment for hASCs to improve adipogenesis and to generate new adipose tissue. On the other hand, the cell dosage choose $2 \times 10^{7}$ is according our previous data that uncultured stromal vascular fraction loaded onto scaffolds can be regenerated new adipose tissue in vitro.[65]

Liu et al. [66] reported that disulfide-crosslinked hyaluronan films do not facilitate cellular adhesion and protein adsorption. Techniques developed to improve cell adhesion to thiol-modified hyaluronan include the incorporation of fibronectin domains [67] or crosslinked gelatin [68]. Tholpady et al. [69] established that mature adipocytes maintain their phenotype when cultured in suspension and de-differentiate into a precursor state when cultured under cell-adhesive conditions. Flynn et al. [36] later confirmed that cells in non-adhesive-crosslinked hyaluronan-alone constructs had significantly higher GPDH activity level. In the HA gel (RESTYLANE ${ }^{\circledR}$ ) particles, the molecules are connected to each other. The molecular weight of a HA gel particle is higher than 100 billion. The residence time of HA gel is around 4-14 months according on the tissue of implantation, the concentration of stabilized HA gel and the existence of inflammation reaction. (www.q-med.com) In the current study, microscope observation indicated that HA gel optimized the seeding and proliferation of inducted hASCs over the entire carrier (Fig. 2). We speculate that adhesion of hASCs to HA gel does not impact the proliferation and differentiation response. HA gel structure may be a good receptor for CD44 and for adhesion of hASCs.

Histological studies after hematoxylin and eosin (H\&E) stain and Oil-Red O stain indicated that all newly formed adipose tissue samples were viable adipocytes with large, intact, and highly uniform vacuole-like spaces with very small cell nuclei. Oil-Red O stain confirmed that these spaces were lipid droplets. Neovascularization with red blood cells in endothelial lumen was also noted between HA gel and new adipose tissue. The newly formed adipose tissue clearly originated via Alu gene expression, which is unique to humans. This result suggested that the new adipose tissue is proliferated by human tissue $[30,70]$. However, in figure 5, line 3, the hASCs did not express positive gene, that is because hASCs did not homing in the injection site.

Neovascular vessels supplied these newly formed adipose tissues, which is not possible in free fat grafting due to central fat necrosis caused by poor circulation. The hASCs are also known to secrete vascular endothelial growth factor (VEGF) [71], which enhances angiogenesis. Finally, HA gel is biodegradable and bioabsorbable. Its gradual replacement by newly forming adipose tissues eventually (Fig. 4) and achieve ideal filler, durable and long-term results.

The limitation of this study is that we did not test the long-term effects (>8 weeks of follow-up) of complete bioabsorption of HA gel with hASCs on in vivo adipogenesis. Long-term use of tissue filler to restore adipose tissue defects and to maintain soft tissue is still problematic. This study indicated that mesenchymal stem cells cultured in vivo on HA gel form new adipose tissue and provide a volumetrically stable injectable filler as the HA gel scaffold gradually biodegraded. Further long-term in vivo studies are needed to determine when HA gel completely disintegrates after injection [33]. Although this method obtained new adipose tissue, the detailed molecular mechanisms whereby HA gel promotes the adipogenesis, proliferation, mobility of inducted stem cells and issue of tumorigenesis [72].

\section{Conclusion}

This study demonstrated not only the successful culture of hASCs on HA gel, but also their full proliferation and differentiation into adipocytes. The newly formed adipose tissue maintains the efficacy of the filler throughout the gradual biodegradation and bioabsorption of the HA gel. This technique is a prom- 
ising approach for developing long-lasting soft tissue filler that would enable the use of HA gel for autologous hASC transplant.

\section{Acknowledgments}

The authors acknowledge Yen-Hsin Kuo and Shu-Chuan Lee for assistance in preparing figures. This work was supported by the National Science Council, Taiwan (102-2314-B-037-014-MY2), Kaohsiung Medical University (KMU-Q-103002, KMU-TP103G02, KMU-TP103G04, KMU-TP103G05), Kaohsiung Medical University Hospital (KMUH-1R23, KMUH103-3R22).

\section{Competing Interests}

The authors have declared that no competing interest exists.

\section{References}

1. American Society of Plastic Surgeons (ASPS). 2012 Plastic Surgery Procedural Statistics, Top 5 Cosmetic Surgical Procedures. US: ASPS. 2012

2. Eppley BL and Dadvand B. Injectable soft-tissue fillers: clinical overview. Plast Reconstr Surg. 2006; 118: 98e-106e.

3. Coleman SR. Structural fat grafts: the ideal filler? Clin Plast Surg. 2001; 28: 111-119.

4. Phulpin B, Gangloff P, Tran N, et al. Rehabilitation of irradiated head and neck tissues by autologous fat transplantation. Plast Reconstr Surg. 2009; 123: 1187-1197.

5. Sariguney $\mathrm{Y}$, Demir $\mathrm{YH}$, Yavuzer R, et al. Scar tissue graft as a filler for soft tissue augmentation. Aesthetic Plast Surg. 2007; 31: 692-696.

6. Coleman SR. Structural fat grafting: more than a permanent filler. Plast Reconstr Surg. 2006; 118: 108S-120S.

7. Gomillion CT and Burg KJ. Stem cells and adipose tissue engineering. Biomaterials. 2006; 27: 6052-6063.

8. Kantanen DJ, Closmann JJ, Rowshan HH. Abdominal fat harvest technique and its uses in maxillofacial surgery. Oral Surg Oral Med Oral Pathol Oral Radiol Endod. 2010;

9. Guyuron B and Majzoub RK. Facial augmentation with core fat graft: a preliminary report. Plast Reconstr Surg. 2007; 120: 295-302.

10. Chajchir A, Benzaquen I, Wexler E, et al. Fat injection. Aesthetic Plast Surg. 1990; 14: 127-136.

11. Coleman SR and Saboeiro AP. Fat grafting to the breast revisited: safety and efficacy. Plast Reconstr Surg. 2007; 119: 775-785; discussion 786-777.

12. Missana MC, Laurent I, Barreau L, et al. Autologous fat transfer in reconstructive breast surgery: indications, technique and results. Eur J Surg Oncol. 2007: 33: 685-690.

13. Halbleib M, Skurk T, de Luca C, et al. Tissue engineering of white adipose tissue using hyaluronic acid-based scaffolds. I: in vitro differentiation of human adipocyte precursor cells on scaffolds. Biomaterials. 2003; 24: 3125-3132.

14. Pan L, Ren Y, Cui F, et al. Viability and differentiation of neural precursors on hyaluronic acid hydrogel scaffold. J Neurosci Res. 2009; 87: 3207-3220.

15. Gentleman E, Nauman EA, Livesay GA, et al. Collagen composite biomaterials resist contraction while allowing development of adipocytic soft tissue in vitro. Tissue Eng. 2006; 12: 1639-1649.

16. Oliveira SM, Ringshia RA, Legeros RZ, et al. An improved collagen scaffold for skeletal regeneration. J Biomed Mater Res A. 2010

17. McCullen S, Miller P, Gittard S, et al. In situ collagen polymerization of layered cell-seeded electrospun scaffolds for bone tissue engineering applications. Tissue Eng Part C Methods. 2010;

18. Tan W, Krishnaraj R, Desai TA. Evaluation of nanostructured composite collagen--chitosan matrices for tissue engineering. Tissue Eng. 2001; 7: 203-210.

19. Heinemann $C$, Heinemann S, Bernhardt $A$, et al. In vitro osteoclastogenesis on textile chitosan scaffold. Eur Cell Mater. 2010; 19: 96-106.

20. Awad HA, Wickham MQ, Leddy HA, et al. Chondrogenic differentiation of adipose-derived adult stem cells in agarose, alginate, and gelatin scaffolds. Biomaterials. 2004; 25: 3211-3222.

21. Yang C, Frei H, Rossi FM, et al. The differential in vitro and in vivo responses of bone marrow stromal cells on novel porous gelatin-alginate scaffolds. J Tissue Eng Regen Med. 2009; 3: 601-614.

22. Wang L, Dormer NH, Bonewald L, et al. Osteogenic differentiation of human umbilical cord mesenchymal stromal cells in polyglycolic acid scaffolds. Tissue Eng Part A. 2010;
23. Dong $\mathrm{Y}$, Yong T, Liao S, et al. Distinctive degradation behaviors of electrospun polyglycolide, poly(DL-lactide-co-glycolide), and poly(L-lactide-co-epsiloncaprolactone) nanofibers cultured with/without porcine smooth muscle cells. Tissue Eng Part A. 2010; 16: 283-298.

24. Wang C, Cen L, Yin S, et al. A small diameter elastic blood vessel wall prepared under pulsatile conditions from polyglycolic acid mesh and smooth muscle cells differentiated from adipose-derived stem cells. Biomaterials. 2010; 31: 621-630.

25. Shao HJ, Chen CS, Lee IC, et al. Designing a three-dimensional expanded polytetrafluoroethylene-poly(lactic-co-glycolic acid) scaffold for tissue engineering. Artif Organs. 2009; 33: 309-317.

26. Karp JM, Shoichet MS, Davies JE. Bone formation on two-dimensional poly(DL-lactide-co-glycolide) (PLGA) films and three-dimensional PLGA tissue engineering scaffolds in vitro. J Biomed Mater Res A. 2003; 64: 388-396.

27. Alhadlaq A, Tang M, Mao JJ. Engineered adipose tissue from human mesenchymal stem cells maintains predefined shape and dimension: implications in soft tissue augmentation and reconstruction. Tissue Eng. 2005; 11: $556-566$

28. Savina IN, Dainiak M, Jungvid $H$, et al. Biomimetic macroporous hydrogels: protein ligand distribution and cell response to the ligand architecture in the scaffold. J Biomater Sci Polym Ed. 2009; 20: 1781-1795.

29. Kim BS, Baez CE, Atala A. Biomaterials for tissue engineering. World J Urol. 2000; 18: 2-9.

30. Qureshi SJ, Porteous DJ, Brookes AJ. Alu-based vectorettes and splinkerettes. More efficient and comprehensive polymerase chain reaction amplification of human DNA from complex sources. Genet Anal Tech Appl. 1994; 11: 95-101.

31. Hamilton RG, Strobos J, Adkinson NF, Jr. Immunogenicity studies of cosmetically administered nonanimal-stabilized hyaluronic acid particles. Dermatol Surg. 2007; 33 Suppl 2: S176-185.

32. Matarasso SL, Carruthers JD, Jewell ML. Consensus recommendations for soft-tissue augmentation with nonanimal stabilized hyaluronic acid (Restylane). Plast Reconstr Surg. 2006; 117: 3S-34S; discussion 35S-43S

33. Lemperle G, Morhenn V, Charrier U. Human histology and persistence of various injectable filler substances for soft tissue augmentation. Aesthetic Plast Surg. 2003; 27: 354-366; discussion 367.

34. Choi JS, Yang HJ, Kim BS, et al. Human extracellular matrix (ECM) powders for injectable cell delivery and adipose tissue engineering. J Control Release. 2009; 139: 2-7.

35. Hemmrich $K$ and von Heimburg D. Biomaterials for adipose tissue engineering. Expert Rev Med Devices. 2006; 3: 635-645.

36. Flynn L, Prestwich GD, Semple JL, et al. Adipose tissue engineering with naturally derived scaffolds and adipose-derived stem cells. Biomaterials. 2007; 28: 3834-3842.

37. Lin SD, Wang KH, Kao AP. Engineered adipose tissue of predefined shape and dimensions from human adipose-derived mesenchymal stem cells. Tissue Eng Part A. 2008; 14: 571-581.

38. Zacchi V, Soranzo C, Cortivo R, et al. In vitro engineering of human skin-like tissue. J Biomed Mater Res. 1998; 40: 187-194.

39. Aigner J, Tegeler J, Hutzler P, et al. Cartilage tissue engineering with novel nonwoven structured biomaterial based on hyaluronic acid benzyl ester. J Biomed Mater Res. 1998; 42: 172-181.

40. Solchaga LA, Dennis JE, Goldberg VM, et al. Hyaluronic acid-based polymers as cell carriers for tissue-engineered repair of bone and cartilage. J Orthop Res. 1999; 17: 205-213.

41. von Heimburg $D$, Zachariah $S$, Low $A$, et al. Influence of different biodegradable carriers on the in vivo behavior of human adipose precursor cells. Plast Reconstr Surg. 2001; 108: 411-420; discussion 421-412.

42. Lin TM, Tsai JL, Lin SD, et al. Accelerated growth and prolonged lifespan of adipose tissue-derived human mesenchymal stem cells in a medium using reduced calcium and antioxidants. Stem Cells Dev. 2005; 14: 92-102.

43. Zuk PA, Zhu M, Mizuno $\mathrm{H}$, et al. Multilineage cells from human adipose tissue: implications for cell-based therapies. Tissue Eng. 2001; 7: 211-228.

44. Zuk PA, Zhu M, Ashjian P, et al. Human adipose tissue is a source of multipotent stem cells. Mol Biol Cell. 2002; 13: 4279-4295.

45. Lahiri A and Waters R. Experience with Bio-Alcamid, a new soft tissue endoprosthesis. J Plast Reconstr Aesthet Surg. 2007; 60: 663-667.

46. von Buelow S, von Heimburg D, Pallua N. Efficacy and safety of polyacrylamide hydrogel for facial soft-tissue augmentation. Plast Reconstr Surg 2005; 116: 1137-1146; discussion 1147-1138.

47. Rohrich RJ, Ghavami A, Crosby MA. The role of hyaluronic acid fillers (Restylane) in facial cosmetic surgery: review and technical considerations. Plast Reconstr Surg. 2007; 120: 41S-54S.

48. Klein AW. Soft tissue augmentation 2006: filler fantasy. Dermatol Ther. 2006; 19: 129-133.

49. Humphrey CD, Arkins JP, Dayan SH. Soft tissue fillers in the nose. Aesthet Surg J. 2009; 29: 477-484.

50. Marmur ES, Al Quran H, De Sa Earp AP, et al. A five-patient satisfaction pilot study of calcium hydroxylapatite injection for treatment of aging hands. Dermatol Surg. 2009; 35: 1978-1984.

51. Tezel A and Fredrickson GH. The science of hyaluronic acid dermal fillers. J Cosmet Laser Ther. 2008; 10: 35-42.

52. Peer LA. Cell survival theory versus replacement theory. Plast reconstr surg (1946). 1955; 16: 161-168

53. Lowe NJ, Maxwell CA, Lowe P, et al. Hyaluronic acid skin fillers: adverse reactions and skin testing. J Am Acad Dermatol. 2001; 45: 930-933. 
54. Inamed Corporation. Product Information Sheet on CosmoDerm and CosmoPlast. Inamed Corp. 2003;

55. Tzikas TL. A 52-month summary of results using calcium hydroxylapatite for facial soft tissue augmentation. Dermatol Surg. 2008; 34 Suppl 1: S9-15.

56. Stillaert FB, Di Bartolo C, Hunt JA, et al. Human clinical experience with adipose precursor cells seeded on hyaluronic acid-based spongy scaffolds. Biomaterials. 2008; 29: 3953-3959.

57. Kleinman HK, Philp D, Hoffman MP. Role of the extracellular matrix in morphogenesis. Curr Opin Biotechnol. 2003; 14: 526-532.

58. Badylak SF. The extracellular matrix as a scaffold for tissue reconstruction. Semin Cell Dev Biol. 2002; 13: 377-383.

59. Howard D, Buttery LD, Shakesheff KM, et al. Tissue engineering: strategies, stem cells and scaffolds. J Anat. 2008; 213: 66-72.

60. Wu SC, Chang JK, Wang CK, et al. Enhancement of chondrogenesis of human adipose derived stem cells in a hyaluronan-enriched microenvironment. Biomaterials. 2010; 31: 631-640.

61. Gimble J and Guilak F. Adipose-derived adult stem cells: isolation, characterization, and differentiation potential. Cytotherapy. 2003; 5: 362-369.

62. Zannettino AC, Paton S, Arthur A, et al. Multipotential human adipose-derived stromal stem cells exhibit a perivascular phenotype in vitro and in vivo. J Cell Physiol. 2008; 214: 413-421.

63. Gronthos S, Franklin DM, Leddy HA, et al. Surface protein characterization of human adipose tissue-derived stromal cells. J Cell Physiol. 2001; 189: 54-63.

64. Yang MC, Chi NH, Chou NK, et al. The influence of rat mesenchymal stem cell CD44 surface markers on cell growth, fibronectin expression, and cardiomyogenic differentiation on silk fibroin - Hyaluronic acid cardiac patches. Biomaterials. 2010; 31: 854-862.

65. Lin SD, Huang SH, Lin YN, et al. Engineering adipose tissue from uncultured human adipose stromal vascular fraction on collagen matrix and gelatin sponge scaffolds. Tissue Eng Part A. 2011; 17: 1489-1498.

66. Liu Y, Zheng Shu X, Prestwich GD. Biocompatibility and stability of disulfide-crosslinked hyaluronan films. Biomaterials. 2005; 26: 4737-4746.

67. Ghosh K, Ren XD, Shu XZ, et al. Fibronectin functional domains coupled to hyaluronan stimulate adult human dermal fibroblast responses critical for wound healing. Tissue Eng. 2006; 12: 601-613.

68. Shu XZ, Ahmad S, Liu Y, et al. Synthesis and evaluation of injectable, in situ crosslinkable synthetic extracellular matrices for tissue engineering. J Biomed Mater Res A. 2006; 79: 902-912.

69. Tholpady SS, Aojanepong C, Llull R, et al. The cellular plasticity of human adipocytes. Ann Plast Surg. 2005; 54: 651-656.

70. Batzer MA and Deininger PL. A human-specific subfamily of Alu sequences. Genomics. 1991; 9: 481-487.

71. Rehman J, Traktuev D, Li J, et al. Secretion of angiogenic and antiapoptotic factors by human adipose stromal cells. Circulation. 2004; 109: 1292-1298.

72. Nerem RM. Tissue engineering: the hope, the hype, and the future. Tissue Eng. 2006; $12: 1143-1150$. 